\title{
Role of ultrafast dissociation in the fragmentation of chlorinated methanes
}

Cite as: J. Chem. Phys. 148, 174301 (2018); https://doi.org/10.1063/1.5026720

Submitted: 23 February 2018 . Accepted: 16 April 2018 . Published Online: 02 May 2018

E. Kokkonen (D), K. Jänkälä (D), M. Patanen (D), W. Cao (D), M. Hrast, K. Bučar, M. Žitnik, and M. Huttula
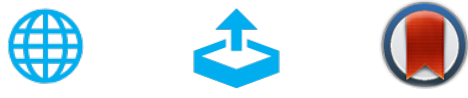

View Online

Export Citation

\section{ARTICLES YOU MAY BE INTERESTED IN}

Excited state non-adiabatic dynamics of the smallest polyene, trans 1,3-butadiene. I. Timeresolved photoelectron-photoion coincidence spectroscopy

The Journal of Chemical Physics 148, 164302 (2018); https://doi.org/10.1063/1.5016452

Doubly charged coronene clusters-Much smaller than previously observed

The Journal of Chemical Physics 148, 174303 (2018); https://doi.org/10.1063/1.5028393

Communication: Gas-phase structural isomer identification by Coulomb explosion of aligned molecules

The Journal of Chemical Physics 148, 091102 (2018); https://doi.org/10.1063/1.5023441

The Journal

of Chemical Physics

The Emerging Investigators Special Collection and Awards Recognizing the excellent work of early career researchers! 


\title{
Role of ultrafast dissociation in the fragmentation of chlorinated methanes
}

\author{
E. Kokkonen, ${ }^{1, a)}$ K. Jänkälä, ${ }^{1}$ M. Patanen, ${ }^{1}$ W. Cao, ${ }^{1}$ M. Hrast,${ }^{2}$ K. Bučar, ${ }^{2}$ M. Žitnik, ${ }^{2,3}$ \\ and M. Huttula ${ }^{1}$ \\ ${ }^{1}$ Nano and Molecular Systems Research Unit, University of Oulu, P.O. Box 3000, FIN-90014 Oulu, Finland \\ ${ }^{2}$ Jožef Stefan Institute, P.O. Box 3000, SI-1001 Ljubljana, Slovenia \\ ${ }^{3}$ Faculty of Mathematics and Physics, University of Ljubljana, Jadranska 19, SI-1000 Ljubljana, Slovenia
}

(Received 23 February 2018; accepted 16 April 2018; published online 2 May 2018)

\begin{abstract}
Photon-induced fragmentation of a full set of chlorinated methanes $\left(\mathrm{CH}_{3} \mathrm{Cl}, \mathrm{CH}_{2} \mathrm{Cl}_{2}, \mathrm{CHCl}_{3}, \mathrm{CCl}_{4}\right)$ has been investigated both experimentally and computationally. Using synchrotron radiation and electron-ion coincidence measurements, the dissociation processes were studied after chlorine $2 p$ electron excitation. Experimental evidence for $\mathrm{CH}_{3} \mathrm{Cl}$ and $\mathrm{CH}_{2} \mathrm{Cl}_{2}$ contains unique features suggesting that fast dissociation processes take place. By contrast, $\mathrm{CHCl}_{3}$ and $\mathrm{CCl}_{4}$ molecules do not contain the same features, hinting that they experience alternative mechanisms for dissociation and charge migration. Computational work indicates differing rates of charge movement after the core-excitation, which can be used to explain the differences observed experimentally. Published by AIP Publishing. https://doi.org/10.1063/1.5026720
\end{abstract}

\section{INTRODUCTION}

Excitation of an inner-shell electron in molecules often results in a distinctive fragmentation pattern governed by the resulting electronic relaxation pathways as well as nuclear dynamics. In the context of chlorinated methanes, fragmentation following an inner-shell excitation can be an effective way of releasing chlorine from the molecules. In atmospheric sciences, the depletion of ozone has been linked to reactions with chlorine atoms and radicals. ${ }^{1}$ Collisions between ozone molecules and atomic chlorine are highly efficient at producing chlorine monoxide and oxygen. ${ }^{1}$ Chlorine monoxide can react further producing atomic chlorine, leading to a cycle where ozone is destroyed into molecular oxygen but no chlorine atoms are consumed. ${ }^{1}$ Here we report several mechanisms related to atomic chlorine production from chlorinated methanes via core-electron excitation.

In industrial applications, chlorinated methanes are used mainly as precursors. The processing of silicones, various solvents, new hydrochlorofluorocarbons, and chlorofluorocarbons all have different chlorinated methanes incorporated in their manufacture. As the global consumption of these compounds is increasing, the impact on atmosphere demands further study. ${ }^{2-4}$ It has been found that the atmospheric concentrations of some chlorinated methanes have been rising in the 21 st century, ${ }^{5}$ and all of them have natural and anthropogenic sources. ${ }^{6}$

Ultrafast dissociation (UFD) has been shown to be an effective way of releasing the molecular internal energy after electronic core excitation into an unoccupied molecular orbital with a strong antibonding character. ${ }^{7}$ In this paper,

\footnotetext{
a)Electronic mail: esko.kokkonen@maxiv.lu.se; Current address: MAX IV Laboratory, Lund University, P.O. Box 118, SE-221 00 Lund, Sweden.
}

dissociation is discussed as proceeding by two-steps, i.e., occurring before or after the emission of an Auger electron. This distinction is an approximation, as in reality the system is only truly explained by a one-step process once the wavepacket dynamics and scattering times are on a similar time frame. ${ }^{8}$

The time scale of molecular dissociation is rather sensitive to the masses of the constituent particles involved in the process. For example, in the case of increasing the mass of the neutral fragment by a factor of 15 (e.g., when moving from $\mathrm{HCl}$ to $\mathrm{CH}_{3} \mathrm{Cl}$ ) and assuming rigid motion of fragments, dissociation is expected to slow down considerably, ${ }^{8,9}$ which in turn promotes competing molecular decay (i.e., electronic relaxation that takes place before the nuclear rearrangement).

Chlorinated methanes have been studied intensively by numerous X-ray based techniques. The fragmentation has been widely studied using electron-ion coincidence techniques. ${ }^{10-17}$ The electronic structure of the valence region and its relationship to fragmentation has been investigated by various UV and vacuum ultraviolet (VUV) excitation studies. ${ }^{18-23}$ The dissociation dynamics and fragment production have been investigated in the vicinity of the $\mathrm{Cl} 2 p$ absorption edge in gaseous and condensed $\mathrm{CH}_{2} \mathrm{Cl}_{2},{ }^{24,25} \mathrm{CHCl}_{3},{ }^{26}$ and $\mathrm{CCl}_{4}{ }^{27}$ using partial ion yield techniques. Resonant inelastic X-ray scattering (RIXS) is also a common method for probing dissociation and nuclear dynamics. For chlorinated methanes, RIXS has often been used in conjunction with carbon $1 s$ excitation. ${ }^{28-32}$

In the present experiment, we investigate the dissociation of four chlorinated methanes $\left(\mathrm{CH}_{3} \mathrm{Cl}, \mathrm{CH}_{2} \mathrm{Cl}_{2}, \mathrm{CHCl}_{3}\right.$, and $\mathrm{CCl}_{4}$ ) by exciting a chlorine $2 p$ core electron into an unoccupied $\sigma^{*}$ type orbital with a strong antibonding character. The potential fragmentation pathways are studied using 
Auger-electron fragment-ion coincidence spectroscopy. Special interest is given to whether UFD is a prominent process in the different systems. These four similar molecules provide an excellent test case for studying the details of the dissociation pathways initiated by an identical resonance excitation. In all four molecules, the detected electrons were from the spectator decay of the L-VV Auger decay process. All created positive ions were subsequently detected. Fragmentation of $\mathrm{CH}_{3} \mathrm{Cl}$ and $\mathrm{CH}_{2} \mathrm{Cl}_{2}$ has been studied by Miron et al. ${ }^{33}$ and recently by Alcantara et al. ${ }^{25}$ respectively, using similar methods. We complement these studies with a systematic study of these four molecules under similar experimental conditions.

\section{EXPERIMENTS}

The experiments were conducted on the I411 beamline ${ }^{34,35}$ of the MAX IV Laboratory in Lund, Sweden. A Scienta SES-200 type hemispherical deflection analyzer (HDA) ${ }^{36}$ was used to measure the kinetic energies of the emitted photo and Auger electrons and a two-field Wiley-McLaren type timeof-flight mass spectrometer (TOFMS ${ }^{37}$ for the measurements of the mass-to-charge ratios of the ions. The two spectrometers were operated in the coincidence mode where the successful electron detection initiates the TOFMS to record the masses of the produced ions.

The TOFMS consists of an extraction, acceleration, and drift regions, each with lengths of approximately $15 \mathrm{~mm}$, $100 \mathrm{~mm}$, and $660 \mathrm{~mm}$. The extraction region has two circular meshes on the either side to ensure a homogeneous electric field as well as to allow the passage of electrons and ions to the opposite directions. The acceleration region houses a series of aluminium rings with resistors in series to distribute the voltage for each ring in order to further enhance the homogeneity of the accelerating field. To get a good mass resolution, the TOFMS is equipped with a long drift tube allowing the different mass-to-charge particles to be differentiated.

The voltages that create the extraction and acceleration fields are optimized according to the Wiley-McLaren conditions for spatial focusing. ${ }^{37}$ The voltage ratio between the acceleration $\left(U_{\text {acc }}\right)$ and extraction $\left(U_{\text {ext }}\right)$ regions in these experiments was found to be about $U_{\mathrm{acc}} / U_{\mathrm{ext}}=7.40$. Here, acceleration voltages of about $2 \mathrm{kV}$ were used, which yielded electric field strengths of $16 \mathrm{~V} / \mathrm{mm}$ and $20 \mathrm{~V} / \mathrm{mm}$ for the extraction and acceleration regions, respectively.

The detector of the TOFMS consists of three Z-stacked multichannel plates (MCPs) of $75 \mathrm{~mm}$ diameter active area. The detector is equipped with a delay line type position sensitive detector manufactured by Roentdek Handels $\mathrm{GmbH}$. The delay lines create a hexagonal anode structure for optimal particle detection. ${ }^{38}$ In the results provided in this paper, however, the position information of the ions was not used.

The SES-200 electron spectrometer is otherwise unmodified with the exception of the detector, which instead of a CCD camera based detection system houses three MCPs and a resistive anode manufactured by Quantar Technology Inc. The resistive anode allows for a fast electron detection, which is essential for coincidence operation (similar setup has been described previously ${ }^{39,40}$ ). In all measurements here, the HDA was operated with a constant pass energy mode, with a pass energy of $100 \mathrm{eV}$. A curved entrance slit (width $0.8 \mathrm{~mm}$ ) was also used, yielding an approximate analyser broadening of $0.2 \mathrm{eV}$. All measurements were done with the analyser at the so-called "magic angle" of $54.7^{\circ}$ with respect to the linearly polarized synchrotron light. The electron energies were calibrated using the known resonant Auger (RA) spectra of the chlorinated methane samples.

The coincidence logic follows the schemes utilized earlier, ${ }^{17,39,41-45}$ where the electron detection from the HDA sends a signal to the pulsed voltage source (Directed Energy, Inc. model PVX-4450) which raises the voltages in the extraction region for a specified time interval, allowing the measurement of the ion flight times. Due to the inherent differences between the transmissions of the HDA and the TOFMS, there exists a high likelihood of producing false coincidences between electrons and ions that in reality have no correlation. To subtract false coincidence events from the data, the measurement process includes a random triggering sequence. ${ }^{46}$ An external pulse generator provides pulses with a fixed frequency which is interjected between the electron detections. The externally pulsed events are labeled accordingly in the data storage. In the data handling, it is then possible to subtract the randomly triggered events from the electron triggered events so that one is able to only see the real correlations between the electrons and ions.

The coincidence measurement was run at a trigger rate of approximately $100 \mathrm{~Hz}$ from both the electron and random sources (i.e., about $200 \mathrm{~Hz}$ trigger rate in total). This enabled us to do measurements which so-far have been impractical due to the time limitations of a typical synchrotron beamtime. For example, a particular coincidence ion can be monitored as a function of incident photon energy, as was demonstrated by Kokkonen et al. ${ }^{17}$ A similar measurement scheme was later utilized by Sann et al., where they performed photon energy scanned coincidence measurements while also measuring other parameters, such as the electron emission angle dependency. ${ }^{47}$

All samples were introduced to the vacuum chamber via a hypodermic needle inlet in order to increase the pressure in the interaction region. $\mathrm{CH}_{3} \mathrm{Cl}$ gas was used without any further purification while $\mathrm{CH}_{2} \mathrm{Cl}_{2}, \mathrm{CHCl}_{3}$, and $\mathrm{CCl}_{4}$ (all purities $>99.5 \%$ ) which are in liquid form in normal temperature and pressure (NTP) conditions were introduced to the vacuum via several freeze-pump-thaw cycles.

\section{RESULTS}

Figure 1 contains the total ion yield (TIY) spectra of all four molecules recorded in the vicinity of the chlorine $2 p$ absorption edge. These spectra have been used to locate the energies of the $\mathrm{Cl} 2 p_{3 / 2} \rightarrow \sigma^{*}$ resonances. The energy of the resonance is observed to decrease in larger chlorinated methanes. For different chloromethanes, the experimental resonance energies are gathered in Table I together with the lowest unoccupied molecular orbital type (LUMO). The $2 p$ ionization thresholds for all four molecules are at approximately $206 \mathrm{eV}$ 


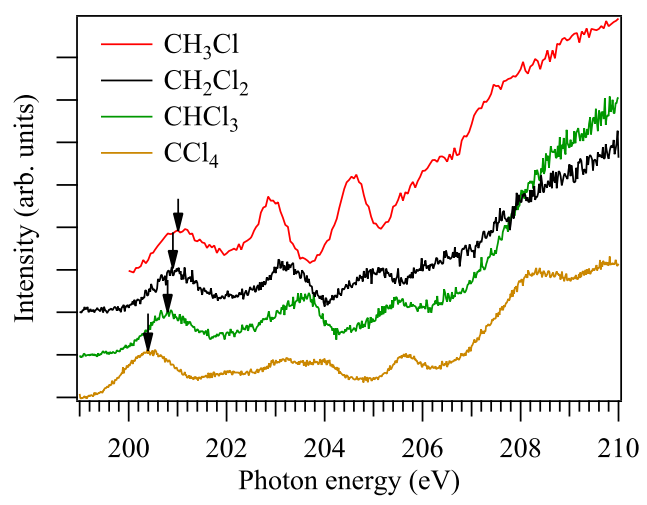

FIG. 1. Total ion yield spectra of $\mathrm{CH}_{3} \mathrm{Cl}, \mathrm{CH}_{2} \mathrm{Cl}_{2}, \mathrm{CHCl}_{3}$, and $\mathrm{CCl}_{4}$. The arrows indicate the photon energies used to excite the $\sigma^{*}$ resonance. The $\mathrm{CCl}_{4}$ spectrum was measured separately on the same beamline using similar experimental arrangements.

(for $2 p_{3 / 2}$ ) and $208 \mathrm{eV}$ (for $2 p_{1 / 2}$ ). ${ }^{10,24,26,27}$ The LUMO orbitals are labeled according to Refs. 11, 24, 26, and 27.

The resonant Auger electron spectra at the $2 p_{3 / 2} \rightarrow \sigma^{*}$ resonance were measured in the same kinetic energy region for all molecules. The spectra are shown in Fig. 2, and they are also divided into three different regions. The regions were chosen based on the RA electron spectrum of $\mathrm{CH}_{3} \mathrm{Cl}$ so that each region contains one of the atomic chlorine spectral lines leading to three ${ }^{2 S+1} \mathrm{~L} 3 p^{-2}$ final states: region $\mathrm{A}$ is centered around ${ }^{1} \mathrm{~S}$, region $\mathrm{B}$ around ${ }^{1} \mathrm{D}$ line, and region $\mathrm{C}$ around ${ }^{3} \mathrm{P}$ line.

The electron-ion coincidence data in this work are presented in the form of coincident ion yields (CIYs), which are composed by summing the amount of coincident ions in each electron energy separately for each fragment ion. Figure 3 contains the CIY spectra of all four chlorinated methanes as well as the RA electron spectra at the top. All spectra are recorded with the photon energy tuned to the selected $2 p_{3 / 2} \rightarrow \sigma^{*}$ resonance, with energies given in Table I.

The kinetic energies of the resonant Auger electrons (for ${ }^{1} \mathrm{~S},{ }^{1} \mathrm{D}$, and ${ }^{3} \mathrm{P}$ final states) were determined from the $\mathrm{Cl}^{+} \mathrm{CIY}$ from $\mathrm{CH}_{3} \mathrm{Cl}$ and were found to be approximately $177.3 \mathrm{eV}$, $179.3 \mathrm{eV}$, and $180.7 \mathrm{eV}$, which are in good agreement with the values reported earlier. ${ }^{8,48,49}$

To clarify further the relative abundance of each observed cation, we have modified the CIY spectra to display the relative yields at each energy step via

$$
I_{i}^{\mathrm{rel}}(E)=\frac{I_{i}^{\mathrm{abs}}(E)}{\sum_{j} I_{j}^{\mathrm{abs}}(E)},
$$

where $I_{i}^{\mathrm{abs}}(E)$ and $I_{i}^{\mathrm{rel}}(E)$ are the absolute and relative CIY for ion $i$ at energy $E$ with the denominator containing the sum of all

TABLE I. Photon energies used for LUMO $\sigma^{*}$ resonance excitation in the different chlorinated methanes.

\begin{tabular}{lcc}
\hline \hline Molecule & $h v(\mathrm{eV})$ & LUMO \\
\hline $\mathrm{CH}_{3} \mathrm{Cl}$ & 201.0 & $8 a_{1}$ \\
$\mathrm{CH}_{2} \mathrm{Cl}_{2}$ & 200.9 & $10 a_{1}$ \\
$\mathrm{CHCl}_{3}$ & 200.8 & $10 a_{1}$ \\
$\mathrm{CCl}_{4}$ & 200.4 & $7 a_{1}$ \\
\hline
\end{tabular}

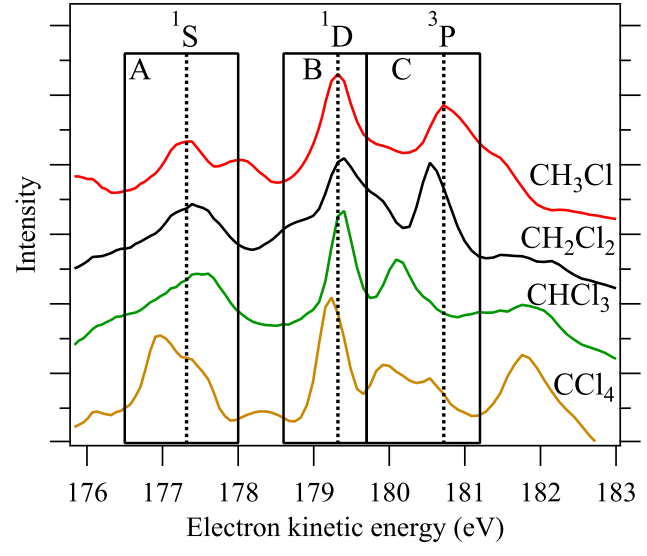

FIG. 2. RA spectra of the four molecules and the three different regions where numerical values for the CIYs have been tabulated. The dashed line indicates the position of the atomic ${ }^{1} \mathrm{~S},{ }^{1} \mathrm{D}$, and ${ }^{3} \mathrm{P}$ states according to Ref. 48 .

absolute CIYs (index $j$ running through all observed cations). The spectra are shown in Fig. 4 for $\mathrm{CH}_{3} \mathrm{Cl}, \mathrm{CH}_{2} \mathrm{Cl}_{2}, \mathrm{CHCl}_{3}$ and $\mathrm{CCl}_{4}$. Additionally, the relative CIYs in each molecule have been stacked on top of each other to make the relative contribution of each ion visually clearer.

The electron intensity weighted averages for the CIY for each fragment ion are then tabulated in Table II for the three regions $\mathrm{A}, \mathrm{B}$, and $\mathrm{C}$.

In all measurements, no doubly or higher order ionized products were seen in coincidence with RA electrons. Apart from hydrogen, all detected cations were recorded with similar detection efficiency. The sum of all detected coincident ions is plotted together with the electron spectrum on the top of each case in Fig. 3. Since the sum spectra and the electron spectra align quite well, it is reasonable to assume that our experiment captures all the main $\sigma^{*}$ fragmentation channels.

\section{A. Chloromethane $\left(\mathrm{CH}_{3} \mathrm{Cl}\right)$}

In previous studies, chloromethane has been classified as an example where UFD is a likely consequence of the $\mathrm{Cl} 2 p_{3 / 2}$ $\rightarrow \sigma^{*}$ excitation. $^{10,33,50,51}$ The dissociation process has been explained to happen while the molecule is still in the coreexcited state. The distance between the carbon and the $\mathrm{Cl}$ atom containing the core-hole can reportedly increase so fast that when the Auger decay occurs, the $\mathrm{Cl}$ atom is relatively far from the methyl group. The energies of the resonant Auger electrons are consequently modified by this process so that the spectrum does not contain broad molecular Auger peaks but sharper atomic-like features instead. For $\mathrm{CH}_{3} \mathrm{Cl}$, this is seen in the $\mathrm{Cl}^{+} \mathrm{CIY}$ in Fig. 3(a) as three sharp lines at the energies corresponding to atomic chlorine resonant Auger final states.

From the CIY results, we can conclude that the most prominent fragmentations subsequent to the RA process (or during the RA process) are

$$
\mathrm{CH}_{3} \mathrm{Cl}+h v \rightarrow \mathrm{CH}_{3} \mathrm{Cl}\left(2 p_{3 / 2}^{-1}\right) \sigma^{*} \rightarrow\left\{\begin{array}{l}
\mathrm{CH}_{3}{ }^{+}+\mathrm{Cl}+e_{\text {Auger }}^{-} \\
\mathrm{CH}_{2}{ }^{+}+\mathrm{H}+\mathrm{Cl}+e_{\text {Auger }}^{-} \\
\mathrm{Cl}^{+}+\mathrm{CH}_{3}+e_{\text {Auger }}^{-}
\end{array}\right.
$$




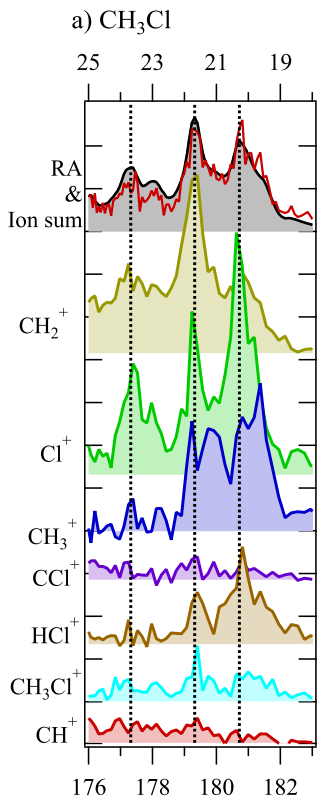

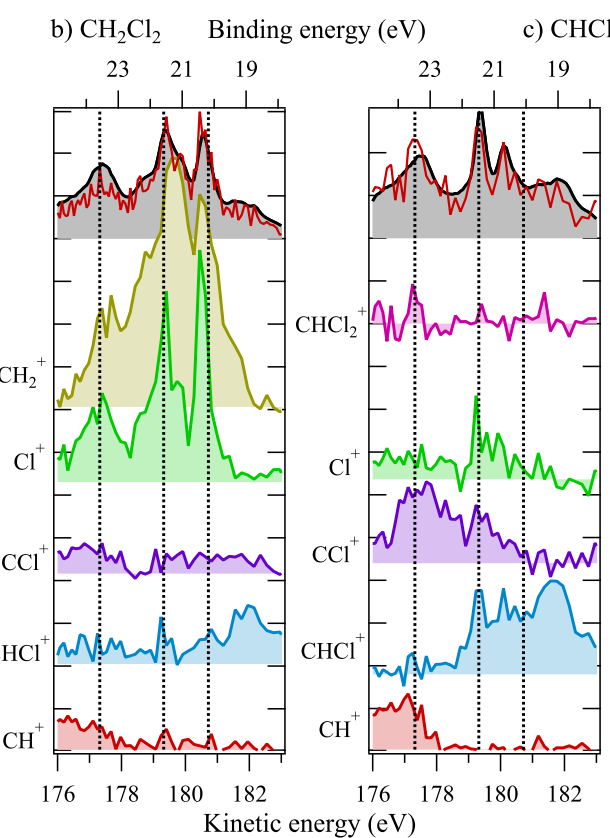

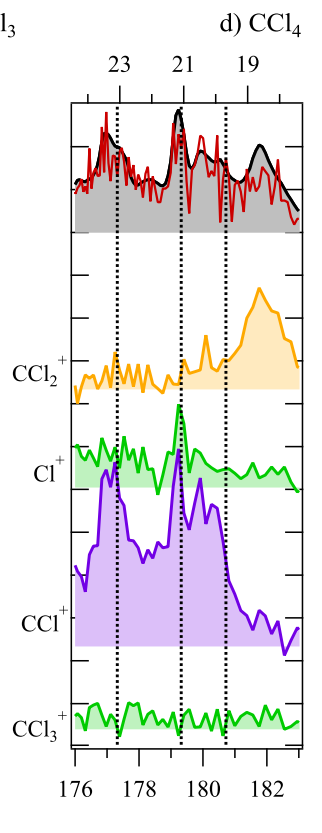

FIG. 3. CIY spectra from $\mathrm{CH}_{3} \mathrm{Cl}$, $\mathrm{CH}_{2} \mathrm{Cl}_{2}, \mathrm{CHCl}_{3}$, and $\mathrm{CCl}_{4}$ molecules taken at the $\sigma^{*}$ resonance indicated in Table I. Each cation is indicated with a different colour and labeled to the left of each panel. The RA electron spectra in each molecule are displayed on the top of each molecule in black. The sum of all detected ions is plotted in red along the RA spectrum. The energies of the atomic chlorine final states are indicated with dashed lines. ${ }^{48}$ Only the most intense CIY spectra are plotted here. since the cations $\mathrm{CH}_{3}{ }^{+}, \mathrm{CH}_{2}{ }^{+}$, and $\mathrm{Cl}^{+}$account for about $70 \%$ of all the detected coincidence ions. The reaction leading to the release of $\mathrm{Cl}^{+}$is most likely the result of a case where the C$\mathrm{Cl}$ distance has grown large enough so that no charge-transfer interaction can occur. The configuration after the Auger decay therefore leaves the excited charge (coming from the $\mathrm{Cl} 2 p$ orbital) in the chlorine atom. This is evidenced by the $\mathrm{Cl}^{+}$ CIY, which, with the current statistical quality, does not show structures originating from the molecular decay. The second reaction leading to a release of $\mathrm{CH}_{3}{ }^{+}$always belongs to the molecular Auger decay regime, i.e., the dissociation occurs after the Auger decay since the excited charge is transferred to the $\mathrm{CH}_{3}{ }^{+}$from the chlorine.

The high amount of $\mathrm{CH}_{2}{ }^{+}$cation seen in coincidence is partially due to direct valence photodissociation. As the inner valence orbital $2 a_{1}$ has a binding energy of approximately $22 \mathrm{eV}$, there is a non-zero probability that direct photoionization of that orbital occurs, even at the photon energy of $201 \mathrm{eV}$. Reaction leading to the emission of $\mathrm{CH}_{2}{ }^{+}$is then

$$
\mathrm{CH}_{3} \mathrm{Cl}+h v \rightarrow \mathrm{CH}_{2}{ }^{+}+\mathrm{Cl}+\mathrm{H}+e_{\text {photo }}^{-},
$$

where the chlorine and hydrogen can also be bound together as $\mathrm{HCl}$. The appearance of $\mathrm{CH}_{2}{ }^{+}$from direct valence photodissociation is confirmed by an off resonance measurement in Fig. 5(a), where the photon energy is $199 \mathrm{eV}$ and therefore below the $\sigma^{*}$ resonance.

$\mathrm{CH}_{3}{ }^{+}$is created at similar final state energies as $\mathrm{HCl}^{+}$, where both require breaking of the $\mathrm{C}-\mathrm{Cl}$ bond. In the creation of $\mathrm{HCl}^{+}$though, there is an additional hydrogen movement from the methyl group toward the chlorine atom. The appearance of $\mathrm{HCl}^{+}$subsequent to the Auger decay in $\mathrm{CH}_{3} \mathrm{Cl}$ has been investigated before and has been attributed to a specific rotation of the methyl group that occurs in one of the Auger final states. ${ }^{17,33}$

The relative CIYs [calculated using Eq. (1)] for all detected cations from $\mathrm{CH}_{3} \mathrm{Cl}$ are shown in Fig. 4(a). There are some changes in the respective final Auger states in the measured energy window. It appears that around the ${ }^{3} \mathrm{P}$

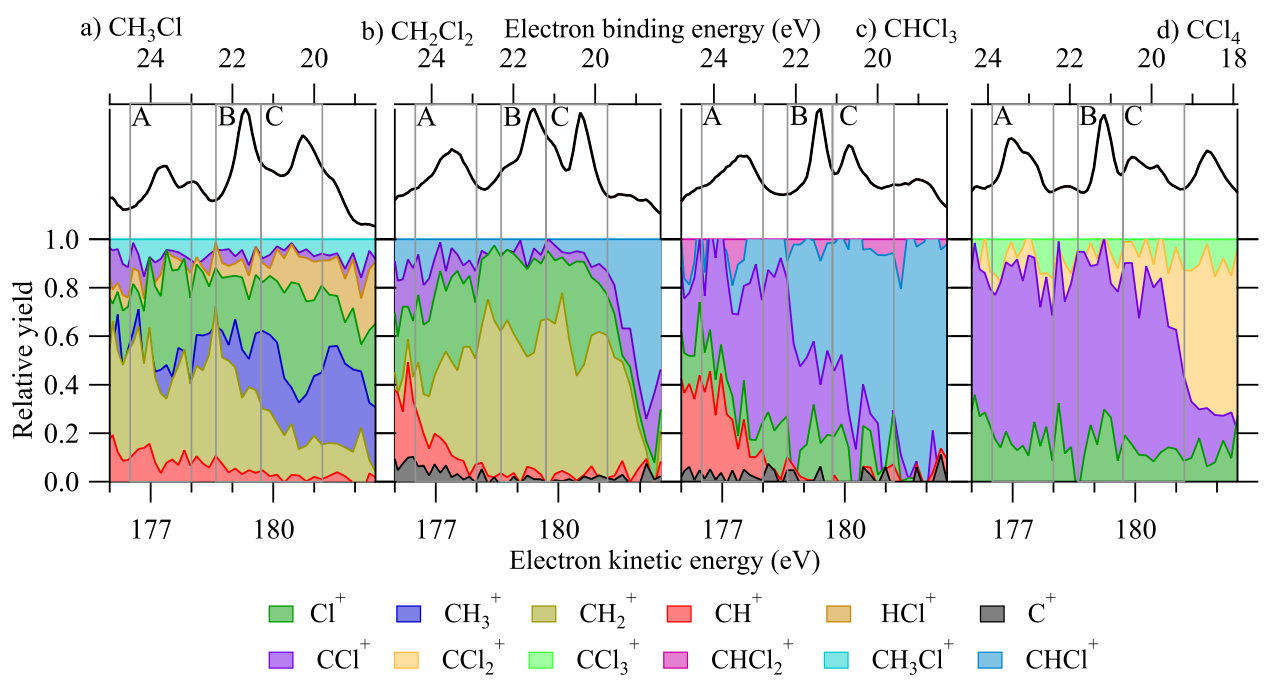

FIG. 4. Relative CIYs from all four molecules and the corresponding Auger spectrum on the top. The relative CIYs are stacked on top of each other to visualize the changes in the fragmentation behavior as a function of electron energy. 
TABLE II. Percentages of detected fragment ions in coincidence with electrons in three different regions. See text and Fig. 2 on how the regions are chosen.

\begin{tabular}{|c|c|c|c|c|c|c|c|c|c|c|c|c|}
\hline & \multicolumn{4}{|c|}{ Region A } & \multicolumn{4}{|c|}{ Region B } & \multicolumn{4}{|c|}{ Region C } \\
\hline & $\mathrm{CH}_{3} \mathrm{Cl}$ & $\mathrm{CH}_{2} \mathrm{Cl}_{2}$ & $\mathrm{CHCl}_{3}$ & $\mathrm{CCl}_{4}$ & $\mathrm{CH}_{3} \mathrm{Cl}$ & $\mathrm{CH}_{2} \mathrm{Cl}_{2}$ & $\mathrm{CHCl}_{3}$ & $\mathrm{CCl}_{4}$ & $\mathrm{CH}_{3} \mathrm{Cl}$ & $\mathrm{CH}_{2} \mathrm{Cl}_{2}$ & $\mathrm{CHCl}_{3}$ & $\mathrm{CCl}_{4}$ \\
\hline $\mathrm{C}^{+}$ & $\ldots$ & 4 & 3 & $\ldots$ & $\ldots$ & 1 & 1 & $\ldots$ & $\ldots$ & 1 & -1 & $\ldots$ \\
\hline $\mathrm{CH}^{+}$ & 12 & 11 & 26 & $\ldots$ & 6 & 3 & 0 & $\ldots$ & 3 & 2 & 1 & $\ldots$ \\
\hline $\mathrm{CH}_{2}{ }^{+}$ & 36 & 33 & $\ldots$ & $\ldots$ & 39 & 55 & $\ldots$ & $\ldots$ & 19 & 56 & $\ldots$ & $\ldots$ \\
\hline $\mathrm{CH}_{3}{ }^{+}$ & 3 & $\ldots$ & $\ldots$ & $\ldots$ & 15 & $\ldots$ & $\ldots$ & $\ldots$ & 25 & $\ldots$ & $\ldots$ & $\ldots$ \\
\hline $\mathrm{Cl}^{+}$ & 32 & 31 & 13 & 17 & 24 & 33 & 19 & 19 & 34 & 31 & 16 & 13 \\
\hline $\mathrm{HCl}^{+}$ & 4 & $\ldots$ & $\ldots$ & $\ldots$ & 7 & $\ldots$ & $\ldots$ & $\ldots$ & 13 & $\ldots$ & $\ldots$ & $\ldots$ \\
\hline $\mathrm{CCl}^{+}$ & 5 & 12 & 49 & 68 & 4 & 3 & 38 & 71 & 2 & 5 & 19 & 65 \\
\hline $\mathrm{CHCl}^{+}$ & $\ldots$ & 9 & 6 & $\ldots$ & $\ldots$ & 6 & 38 & $\ldots$ & $\ldots$ & 5 & 63 & $\ldots$ \\
\hline $\mathrm{CH}_{3} \mathrm{Cl}^{+}$ & 8 & $\ldots$ & $\ldots$ & $\ldots$ & 6 & $\ldots$ & $\ldots$ & $\ldots$ & 5 & $\ldots$ & $\ldots$ & $\ldots$ \\
\hline $\mathrm{CCl}_{2}{ }^{+}$ & $\ldots$ & $\ldots$ & $\ldots$ & 7 & $\ldots$ & $\ldots$ & $\ldots$ & 5 & $\ldots$ & $\ldots$ & $\ldots$ & 18 \\
\hline $\mathrm{CHCl}_{2}{ }^{+}$ & $\ldots$ & $\ldots$ & 3 & $\ldots$ & $\ldots$ & $\ldots$ & 3 & $\ldots$ & $\ldots$ & $\ldots$ & 1 & $\ldots$ \\
\hline $\mathrm{CCl}_{3}{ }^{+}$ & $\ldots$ & $\ldots$ & $\ldots$ & 8 & $\ldots$ & $\ldots$ & $\ldots$ & 4 & $\ldots$ & $\ldots$ & $\ldots$ & 5 \\
\hline
\end{tabular}

states the dissociation favours cleaving the $\mathrm{C}-\mathrm{Cl}$ bond and leaving the charge in either fragment, which is then seen as $\mathrm{Cl}^{+}$or $\mathrm{CH}_{3}{ }^{+}$. These two cations together account for $57 \%$ of all detected cations in region $\mathrm{C}$.

When moving to lower kinetic energies (higher binding energies) in region $\mathrm{A}$, the dominant cation changes to $\mathrm{CH}_{2}{ }^{+}$ and $\mathrm{Cl}^{+}$, which account for $64 \%$ of all ions. This is most likely due to a high probability of direct valence photodissociation to create $\mathrm{CH}_{2}{ }^{+}$.

Region B is in intermediate state between these two cases. Across the whole energy window, it appears that breaking the $\mathrm{C}-\mathrm{Cl}$ bond is the dominant form of fragmentation.

\section{B. Dichloromethane $\left(\mathrm{CH}_{2} \mathrm{Cl}_{2}\right)$}

Fragmentation of dichloromethane in the $\sigma^{*}$ resonance is similar to chloromethane. In $\mathrm{CH}_{2} \mathrm{Cl}_{2}$, it appears that UFD is also a possible dissociation pathway since the $\mathrm{CIY}$ of $\mathrm{Cl}^{+}$has three distinctive peaks which match the atomic chlorine final state energies well, as seen from Fig. 3(b). Broadening of the peaks is also small. By a fitting procedure, we can find that the

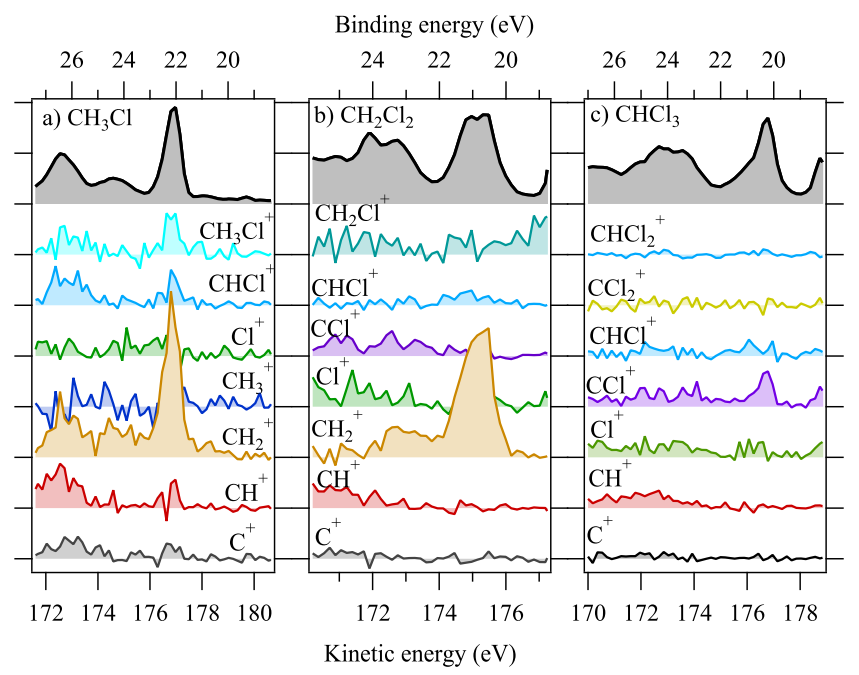

FIG. 5. The electron and CIY spectra for $\mathrm{CH}_{3} \mathrm{Cl}, \mathrm{CH}_{2} \mathrm{Cl}_{2}$, and $\mathrm{CHCl}_{3}$ measured with the photon energy tuned well below the $\sigma^{*}$ resonance (h $v=199 \mathrm{eV}$ for $\mathrm{CH}_{3} \mathrm{Cl}, 196 \mathrm{eV}$ for $\mathrm{CH}_{2} \mathrm{Cl}_{2}$, and $197 \mathrm{eV}$ for $\mathrm{CHCl}_{3}$ ). energies of the ${ }^{1} \mathrm{~S}$ and ${ }^{1} \mathrm{D}$ states remain constant (within fitting errors) with respect to the same states in the chloromethane case. States ${ }^{3} \mathrm{P}$, however, experiences a shift of approximately $-0.2 \mathrm{eV}$.

Fragmentation of $\mathrm{CH}_{2} \mathrm{Cl}_{2}$ subsequent to $\mathrm{Cl} 2 p_{3 / 2}$ excitation to the $\sigma^{*}$ has been reported previously, ${ }^{24,25}$ and it was postulated that ultrafast dissociation is a possible pathway for producing $\mathrm{Cl}^{+}$.

From Fig. 3(b), it is seen that the two most prominent fragmentation pathways are

$$
\mathrm{CH}_{2} \mathrm{Cl}_{2}+h v \rightarrow \mathrm{CH}_{2} \mathrm{Cl}_{2}\left(2 p_{3 / 2}^{-1}\right) \sigma^{*} \rightarrow\left\{\begin{array}{l}
\mathrm{CH}_{2}^{+}+2 \mathrm{Cl}+e_{\text {Auger }}^{-} \\
\mathrm{Cl}^{+}+\mathrm{CH}_{2} \mathrm{Cl}+e_{\text {Auger }}^{-}
\end{array}\right.
$$

as these two cations account for about $70 \%$ of all the detected ions. The present experiment does not reveal whether the neutral chlorine released together with $\mathrm{CH}_{2}{ }^{+}$fragment is $\mathrm{Cl}_{2}$ or two $\mathrm{Cl}$ atoms. In the same manner as with chloromethane, since the spectra contain sharp peaks at the atomic chlorine energies, it is possible for the reaction that produces $\mathrm{Cl}^{+}$to proceed in an ultrafast manner. The competing reaction producing $\mathrm{CH}_{2}{ }^{+}$ has to always happen in the molecular region.

The inner valence states $2 a_{1}$ at binding energy $21.1 \mathrm{eV}^{52}$ produce some $\mathrm{CH}_{2}{ }^{+}$. We thus note that direct photoionization of $2 a_{1}$ orbital and subsequent fragmentation

$$
\mathrm{CH}_{2} \mathrm{Cl}_{2}+h v \rightarrow \mathrm{CH}_{2}^{+}+2 \mathrm{Cl}+e_{\text {photo }}^{-}
$$

is also contributing to the total amount of $\mathrm{CH}_{2}{ }^{+}$that is observed. The appearance of $\mathrm{CH}_{2}{ }^{+}$was confirmed with a coincidence measurement at photon energy below the $\sigma^{*}$ resonance. This is shown in Fig. 5(b).

From the relative CIY results in Fig. 1, we can say that fragments which require breaking of the $\mathrm{C}-\mathrm{Cl}$ bond is the most dominant reaction in all regions $\mathrm{A}, \mathrm{B}$, and $\mathrm{C}$. The amount of $\mathrm{Cl}^{+}$remains constant across the whole window at about $32 \%$. $\mathrm{CH}_{2}{ }^{+}$is found least in region A with about 33\%, whereas it rises to about $56 \%$ in regions $B$ and $C$, which is most likely due to the valence levels that are found in those energies. From the smaller fragments, $\mathrm{CH}^{+}$is slightly more prominent in region $\mathrm{A}$ with its $11 \%$ yield, but it falls to negligible amounts in regions 
B and C. Overall trends in $\mathrm{CH}_{2} \mathrm{Cl}_{2} \mathrm{CIY}$ are similar with $\mathrm{CH}_{3} \mathrm{Cl}$ CIY.

\section{Trichloromethane $\left(\mathrm{CHCl}_{3}\right)$}

The RA spectrum of trichloromethane recorded at the $2 p_{3 / 2} \rightarrow \sigma^{*}$ resonance plotted at the top of Fig. 3(c) shows a structure with a narrow linewidth in region $\mathrm{B}$, similar to other chlorinated methanes. However, it does not appear that the chlorine CIY is straightforwardly responsible for the sharp feature. The largest contribution originates from the $\mathrm{CHCl}^{+}$ fragment which features a peak that appears to form the structure seen in the RA spectrum. $\mathrm{CCl}^{+}$contributes as the second largest intensity, but most of its intensity is in the lower kinetic energies, around region $\mathrm{A}$.

In contrast to $\mathrm{CH}_{3} \mathrm{Cl}$ and $\mathrm{CH}_{2} \mathrm{Cl}_{2}$ molecules, in $\mathrm{CHCl}_{3}$, chlorine is one of the weakest detected cations. The $\mathrm{Cl}^{+} \mathrm{CIY}$ only peaks slightly at the same energy as the atomic chlorine ${ }^{1} \mathrm{D}$ state. Based on this, it seems that a similar process leading to $\mathrm{Cl}^{+}$release as in $\mathrm{CH}_{3} \mathrm{Cl}$, for instance, is not favorable.

The inner valence of $\mathrm{CHCl}_{3}$ has orbital $2 a_{1}$ at a binding energy of $20.8 \mathrm{eV}$ completely in the measured window and orbital $1 e$ at a binding energy $24.6 \mathrm{eV}$ only partially. ${ }^{52}$ Ionization from orbital $2 a_{1}$ seems to produce $\mathrm{CCl}^{+}$due to direct photodissociation, as is evidenced by an off-resonance measurement shown in Fig. 5(c). The fragmentation for the direct photodissociation would therefore be

$$
\mathrm{CHCl}_{3}+h v \rightarrow \mathrm{CCl}^{+}+\mathrm{H}+2 \mathrm{Cl}+e_{\text {photo }}^{-} .
$$

For the trichloromethane case, it appears that the most probable fragmentation pathway, after the resonant Auger decay, leaves at least one $\mathrm{C}-\mathrm{Cl}$ bond intact, while breaking the other two. This is supported by the fact that in all regions the $\mathrm{CCl}^{+}$and $\mathrm{CHCl}^{+}$fragments are the dominant ones (55\% in region $\mathrm{A}, 76 \%$ in $\mathrm{B}$, and $82 \%$ in $\mathrm{C}$ ). The dominant fragmentations are therefore

$$
\begin{aligned}
\mathrm{CHCl}_{3}+h v & \rightarrow \mathrm{CHCl}_{3}\left(2 p_{3 / 2}^{-1}\right) \sigma^{*} \\
& \rightarrow\left\{\begin{array}{l}
\mathrm{CHCl}^{+}+2 \mathrm{Cl}+e_{\text {Auger }}^{-}, \\
\mathrm{CCl}^{+}+2 \mathrm{Cl}+\mathrm{H}+e_{\text {Auger }}^{-}
\end{array}\right.
\end{aligned}
$$

where the composition of the neutral particles is unknown (i.e., the neutral chlorine and hydrogen might also be bound together).

\section{Carbon tetrachloride $\left(\mathrm{CCl}_{4}\right)$}

The resonant Auger spectrum of carbon tetrachloride at the $2 p_{3 / 2} \rightarrow \sigma^{*}$ resonance is shown on the top of Fig. 3(d). The spectrum is similar to the trichloromethane spectrum, and it contains at least one relatively sharp peak. In the same way as in trichloromethane, the peak is mostly connected to final states that produce the $\mathrm{CCl}^{+}$fragment. The contribution of $\mathrm{Cl}^{+}$is small across the whole measured electron energy range, and there are no indications of peak structure in the energies of the atomic ${ }^{1} \mathrm{~S}$ or ${ }^{3} \mathrm{P}$ states. This indicates that UFD is not the process that creates the chlorine signal in the case of $\mathrm{CCl}_{4}$.

Some of the $\mathrm{CCl}^{+}$observed here does not originate from the resonant Auger process but is instead created in direct photodissociation of the inner valence orbitals, which appear at these binding energies. ${ }^{53}$ The fragmentation producing $\mathrm{CCl}^{+}$ in the inner valence would be

$$
\mathrm{CCl}_{4}+h v \rightarrow \mathrm{CCl}^{+}+3 \mathrm{Cl}+e_{\text {photo }}^{-} .
$$

$\mathrm{CCl}_{2}{ }^{+}$is found to be in coincidence with the spectator Auger states at roughly $182 \mathrm{eV}$ kinetic energy.

$\mathrm{Cl}^{+}$and $\mathrm{CCl}_{3}{ }^{+}$are the least detected cations, with $\mathrm{CCl}_{3}{ }^{+}$ exhibiting no discernible structure due to low statistics. $\mathrm{Cl}^{+}$ might be forming a peak at approximately $179 \mathrm{eV}$ kinetic energy, but quantitative information cannot be extracted from it. The most probable fragmentation subsequent to the $\sigma^{*}$ resonant Auger decay is then

$\mathrm{CCl}_{4}+h v \rightarrow \mathrm{CCl}_{4}\left(2 p_{3 / 2}^{-1}\right) \sigma^{*} \rightarrow\left\{\begin{array}{l}\mathrm{CCl}^{+}+3 \mathrm{Cl}+e_{\text {Auger }}^{-} \\ \mathrm{CCl}_{2}^{+}+2 \mathrm{Cl}+e_{\text {Auger }}^{-}\end{array}\right.$.

Similarly as with trichloromethane, carbon tetrachloride also seems to favour breaking two or three $\mathrm{C}-\mathrm{Cl}$ bonds in the measured energy region. Regions $\mathrm{A}, \mathrm{B}$, and $\mathrm{C}$ all have roughly the same amount of $\mathrm{CCl}^{+}$(approximately 65\%-71\%).

\section{DISCUSSION}

In the present work, we show that the fragmentation pathways that produce $\mathrm{Cl}^{+}$are drastically different for the four chlorinated methanes that were investigated. One phenomenological way of explaining the results is with the UFD process. In $\mathrm{CH}_{3} \mathrm{Cl}$ and $\mathrm{CH}_{2} \mathrm{Cl}_{2}$, promotion of a chlorine $2 p$ electron into an antibonding orbital causes dissociation of the molecule while retaining the excited state in the $\mathrm{Cl}$ atom. The excited state then subsequently relaxes in the atom which has a relatively large distance to the other fragment. In $\mathrm{CHCl}_{3}$ and $\mathrm{CCl}_{4}$, this same excitation and similar RA final states do not appear to produce chlorine cation signals of the same intensity.

The evidence to support the likelihood of UFD in $\mathrm{CH}_{3} \mathrm{Cl}$ and $\mathrm{CH}_{2} \mathrm{Cl}_{2}$ is found in the chlorine contributions to the ion yields, i.e., the $\mathrm{Cl}^{+} \mathrm{CIY}$ spectra in each molecule (see Fig. 6). In the case of $\mathrm{CH}_{3} \mathrm{Cl}$ and $\mathrm{CH}_{2} \mathrm{Cl}_{2}$, their similarity indicates that at least a large portion of $\mathrm{RA}$ decays producing $\mathrm{Cl}^{+}$take place in a chlorine atom that is sufficiently far from the rest of the molecule to have an atomic character. The three clearly distinguishable peaks in $\mathrm{Cl}^{+} \mathrm{CIYs}$ of $\mathrm{CH}_{3} \mathrm{Cl}$ and $\mathrm{CH}_{2} \mathrm{Cl}_{2}$ match energetically very well with $\mathrm{RA}$ final states of $\mathrm{HCl}$, in which UFD is well-known.

With the two heavier chlorinated methanes, $\mathrm{CHCl}_{3}$ and $\mathrm{CCl}_{4}$, we cannot get any definitive answers regarding UFD simply from the experimental spectra. Due to the fact that in both cases the $\mathrm{Cl}^{+}$yield is rather low in coincidence with the recorded RA final states, we can only tentatively conclude that even if UFD resulting in $\mathrm{Cl}^{+}$would be viable, it is not a preferred mechanism.

Regardless of the method of fragmentation, an interesting trend is seen in the total amount of chlorine cations observed in coincidence with the RA final states. As the amount of chlorine atoms increases in the molecule, the total amount of coincident $\mathrm{Cl}^{+}$ions seems to decrease (see Table III). Similar trends were seen by $\mathrm{Lu}$ et al., who also found that the $\mathrm{Cl} 2 p_{3 / 2} \rightarrow \sigma^{*}$ excitation only causes small amounts of chlorine cation production in $\mathrm{CHCl}_{3}{ }^{26}$ and $\mathrm{CCl}_{4}{ }^{27}$ when compared to the lighter 


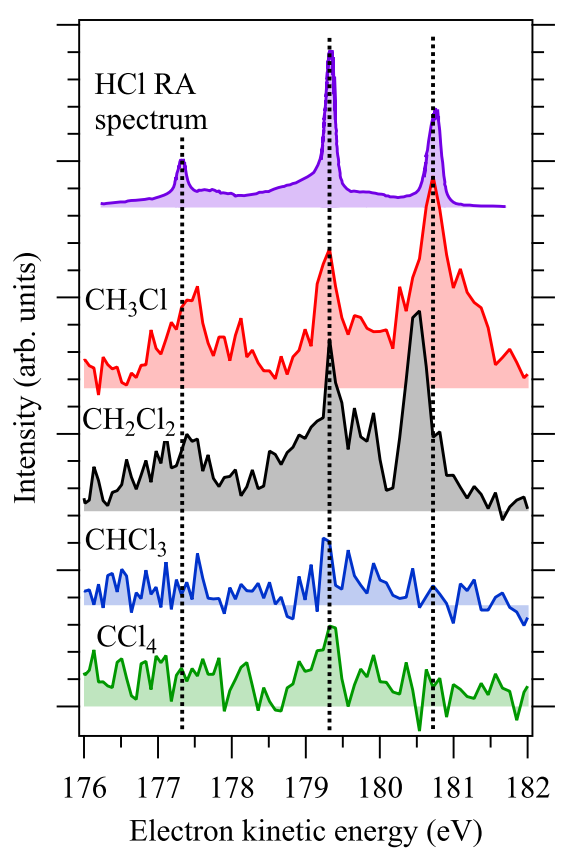

FIG. 6. $\mathrm{Cl}^{+} \mathrm{CIY}$ from the four different chlorinated molecules and the RA spectrum of $\mathrm{HCl}$ for comparison ( $\mathrm{HCl}$ spectrum from Ref. 49).

chlorinated methanes. While their experiments were not done in coincidence with any particular electronic states, the same trend is still observed.

To obtain a better view on the nuclear dynamics and $\mathrm{C}-\mathrm{Cl}$ elongation in the $\mathrm{Cl} 2 p$ core-excited state, we performed quantum chemical calculations for all four molecules. The calculations were done using the Orca software (version 4.0.0). ${ }^{54}$ The shapes of the potential energy curves of the $2 p$ $\rightarrow \sigma^{*}$ excited states were obtained by complete active space self-consistent field $[\operatorname{CASSCF}(7,6)]$ calculations using the socalled equivalent core model (ECM) (see, e.g., Refs. 55-57 and references therein), where the effect of the $2 p$ hole is approximated by replacing one of the $\mathrm{Cl}$ atoms with an $\mathrm{Ar}$ atom. The "Z+1 approximation" was checked by comparing the derivative of the potential energy curve calculated in multireference configuration interaction (MRCI) method to the ECM in the $\mathrm{CHCl}_{3}$ case, for which the MRCI calculation was possible to perform. All calculations were done using def2-TZVP basis sets. ${ }^{58}$ One-dimensional nuclear dynamics along the $\mathrm{C}-\mathrm{Cl}$ distance were then obtained from classical equations of motion, assuming a pseudodiatomic model where the two fragments were approximated as point masses. Here in cases with multiple chlorine atoms, the $\mathrm{C}-\mathrm{Cl}$ coordinate refers to the distance between the core-excited chlorine and the central carbon atom.

TABLE III. Relative amount of observed coincident $\mathrm{Cl}^{+}$cations in each molecule.

\begin{tabular}{ll}
\hline \hline Molecule & $\mathrm{Cl}^{+}(\%)$ \\
\hline $\mathrm{CH}_{3} \mathrm{Cl}$ & 32.3 \\
$\mathrm{CH}_{2} \mathrm{Cl}_{2}$ & 25.8 \\
$\mathrm{CHCl}_{3}$ & 12.2 \\
$\mathrm{CCl}_{4}$ & 15.9 \\
\hline \hline
\end{tabular}

Despite rigorous attempts, the nuclear dynamics calculations were unable to reproduce satisfactory results that would explain the experimental results. The reason is that the calculated excited state potential energy curves were very similar in all four molecules, and by using the lifetime of the $\mathrm{Cl} 2 p$ shell ( $\sim 6.5 \mathrm{fs})$, classical motion along the slopes of the potential energy curves indicates a movement of less than $0.4 \AA$ in the course of the $2 p$ lifetime for all four molecules. At this distance, it is expected that the resonant Auger decay still happens in the molecular regime, which is in disagreement with the experimental results. To explain the fact that the ejected Auger electron would feel an "atomic like" potential from the $\mathrm{Cl}$ fragment, the orbital overlap between the atoms needs to be negligible, which would require a distance of $1 \AA$ or more.

Recently Alcantara et al. calculated potential energy curves for the $\mathrm{Cl} 2 p \rightarrow \sigma^{*}$ excited state in the case of $\mathrm{CH}_{2} \mathrm{Cl}_{2}$ as a function of $\mathrm{C}-\mathrm{Cl}$ distance. ${ }^{25}$ From the calculations they concluded that UFD exists in $\mathrm{CH}_{2} \mathrm{Cl}_{2}$. Their calculated curves agree with ours. However, their conclusion seems to have been primarily made on the basis that the potential energy curve is strongly repulsive. While the strongly repulsive nature of the core-excited state is a necessary requirement for the nuclear rearrangement before Auger decay, it is not a sufficient condition alone because the masses of the fragments and lifetimes of the excited states have to be considered as well. According to our calculations, the slopes of the potential energy curves in all four cases are highly similar which would indicate that all four molecules should fragment roughly in the same manner. This appears not to happen, at least according to the experimental results as seen in Figs. 3 and 6.

Table IV contains the reduced masses and masses of the neutral counterparts of various fragmentation reactions involving the chlorinated methanes investigated in this paper as well as other molecules, such as $\mathrm{HCl}$ and $\mathrm{DCl}$, both of which experience UFD. Included in the table is also the reduced mass for the fragmentation $\mathrm{Cl}_{2}$ molecule, which is known to not show UFD signatures. ${ }^{59}$ Clearly the reduced mass alone is a not a sufficient indicator for the likelihood of UFD, since the reduced mass for $\mathrm{Cl}+\mathrm{Cl}^{+}$reaction is less than the $\mathrm{CH}_{2} \mathrm{Cl}$ $+\mathrm{Cl}^{+}$reaction, which does show some indication of fast dissociation and/or charge movement. Moreover, we note that the reduced masses tabulated in Table IV assume that the neutral counterpart in the dissociation process can be reduced to a point-like source, which naturally is not well defined in cases where there are several atoms in the neutral fragment.

TABLE IV. Reduced masses of various fragmentation processes containing an emitted chlorine cation.

\begin{tabular}{lcc}
\hline \hline Fragmentation reaction & Mass of neutral (u) & Reduced mass (u) \\
\hline $\mathrm{H}+\mathrm{Cl}^{+}$ & 1.00 & 0.98 \\
$\mathrm{D}+\mathrm{Cl}^{+}$ & 2.01 & 1.91 \\
$\mathrm{Cl}+\mathrm{Cl}^{+}$ & 35.45 & 17.73 \\
$\mathrm{CH}_{3}+\mathrm{Cl}^{+}$ & 15.02 & 10.55 \\
$\mathrm{CH}_{2} \mathrm{Cl}_{+} \mathrm{Cl}^{+}$ & 49.47 & 20.65 \\
$\mathrm{CHCl}_{2}+\mathrm{Cl}^{+}$ & 83.91 & 24.92 \\
$\mathrm{CCl}_{3}+\mathrm{Cl}^{+}$ & 118.36 & 27.28 \\
\hline \hline
\end{tabular}


To obtain more information on the charge distribution in the chlorinated methanes upon core-excitation, we carried out Mulliken population analysis, identifying the atomic charges on each nucleus as a function of the $\mathrm{C}-\mathrm{Cl}$ distance (distance between the carbon and the core-excited $\mathrm{Cl}$ atom). The calculations were performed using the StoBedeMon $^{60}$ software. The orbitals were calculated using a variational approach, combined with the transition potential method where both $\mathrm{Cl} 2 p$ and $\sigma^{*}$ orbitals are occupied by half an electron, which describes the excitation process well. ${ }^{61}$ The basis sets were (5211/411/1) for carbon, (3111/111) for hydrogen, and (iii_iglo) for chlorine atoms. The comparison of results obtained by different basis sets shows little differences in electronic charges assigned to different atoms in the molecule.

The results of the Mulliken analysis for all four molecules at the core-excited state as a function of $\mathrm{C}-\mathrm{Cl}$ distance are shown in Fig. 7. The calculated charge deficit is defined as a difference of the charge assigned to the particular atom (in our case, the core-excited chlorine atom) with respect to the neutral atom. For comparison, the percentage of population decayed by RA is presented on the same graph as a function of $\mathrm{C}-\mathrm{Cl}$ distance. A single curve is plotted for all four molecules, given by

$$
1-\exp \left(-\sqrt{\frac{2 d}{a_{0} \tau^{2}}}\right),
$$

where $d$ is the $\mathrm{C}-\mathrm{Cl}$ distance ( 0 being the ground state bond length), $\tau$ is the lifetime of the core-excited state (6.5 fs) and $a_{0}=0.0095 \AA / \mathrm{fs}^{2}$ is the acceleration, assumed to be constant across the considered range of $\mathrm{C}-\mathrm{Cl}$ distance.

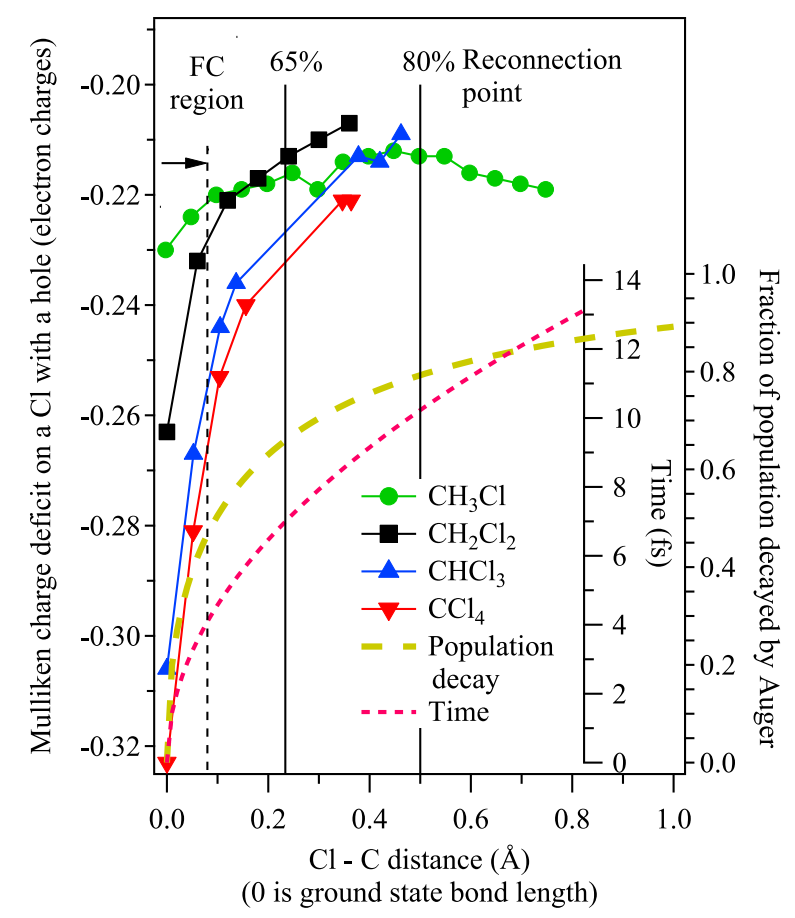

FIG. 7. Results of the Mulliken analysis on the core-excited chlorine atom within each molecule (solid lines). The percentage of population decayed by RA is shown as the dotted yellow line. Using the assumed dissociation acceleration $a_{0}=0.0095 \AA / \mathrm{fs}^{2}$, the time versus the elongated $\mathrm{C}-\mathrm{Cl}$ distance is shown as the dashed red line.
Acceleration $a_{0}$ was calculated from the slope of the coreexcited state's potential energy curve using reduced masses determined in previous work. ${ }^{29}$ It was also found that $a_{0}$ is similar for all four chlorinated methanes. ${ }^{29}$ Finally, the curve in Fig. 7 shows the elapsed time during the dissociation process.

Previous studies have concluded that the initial dissociation dynamics of chlorinated molecules after the $1 s \rightarrow \sigma^{*}$ excitation are mostly determined by the core-excited chlorine and the atom it is connected to (in our case this is always a carbon atom). ${ }^{29,31,32,62}$ The full set of vibrational normal modes were also decomposed, and it was shown that the symmetric and antisymmetric $\mathrm{C}-\mathrm{Cl}$ stretching are the major constituents of the initial movement upon $1 s \rightarrow \sigma^{*}$ photoexcitation. According to Bohinc et al., in the initial phases of the dissociation, only the $\mathrm{C}-\mathrm{Cl}$ bond elongates, while the other atoms remain stationary. After the $\mathrm{C}-\mathrm{Cl}$ distance has increased considerably beyond the Franck-Condon (FC) region, the other atoms start to move as well. This point is called the reconnection point and from there on all the $\mathrm{CX}_{3}$ group members ( $\mathrm{X}=\mathrm{H}, \mathrm{Cl}$ or their combination) are set in the movement. The results obtained from previous study are directly applicable here since $1 s^{-1} \sigma^{*}$ and $2 p_{3 / 2}^{-1} \sigma^{*}$ states have parallel potential energy curves. The reconnection point of molecules studied here is reached at $d \approx 0.5 \AA$ and it is marked on Fig. 7 as a vertical line. At the reconnection point, reached about $10 \mathrm{fs}$ after the photoexcitation, about $80 \%$ of excited population has decayed through RA. After 6.5 fs (the assumed RA lifetime), approximately $65 \%$ of population has decayed by electronic transition. Since the nuclear dynamics change drastically after the reconnection point, our approximation, based on simple initial $\mathrm{C}-\mathrm{Cl}$ distancing, must be abandoned at distances larger than $0.5 \AA$ A.

The Mulliken population analysis shows that after coreexcitation of $\mathrm{CH}_{3} \mathrm{Cl}$, the chlorine atom with the $2 p_{3 / 2}$ hole has about 0.23 electron charges less than a neutral atom (i.e., the atom has become more positive). As the $\mathrm{C}-\mathrm{Cl}$ bond length increases, there is little change in the charge deficit on the chlorine atom.

The heavier chlorinated methanes exhibit a slight contrast to the $\mathrm{CH}_{3} \mathrm{Cl}$ case. In $\mathrm{CCl}_{4}$, for example, we initially see a slightly larger charge deficit of about -0.32 electron charges. However, unlike in $\mathrm{CH}_{3} \mathrm{Cl}$, the analysis here shows that the consequent negative charge is distributed among the carbon and the rest of the (non-excited) chlorine atoms. As the $\mathrm{C}-\mathrm{Cl}$ distance grows in $\mathrm{CCl}_{4}$, the core-excited chlorine gains electron density, i.e., its charge deficit becomes less at about -0.23 electron charges. The results show that in heavier chlorinated methanes, larger amount of charge is exchanged with the rest of the molecule while the initial dissociation dynamics unfold.

However, these changes in the charge distribution are relatively small, making it difficult to estimate their impact on the final fragmentation channels. What should also be taken in account is the Auger decay, which occurs at some point during the dissociation and redistributes the charges again. The extent of the redistribution depends on the $\mathrm{C}-\mathrm{Cl}$ distance and on the nature of the final electronic state, possibly changing the fragmentation pattern. 
Our simulations indicate that the nuclear movement before the Auger decay (first phase of dissociation) is similar in all four chlorinated methanes. The observed difference in the coincident chlorine contribution must then originate from the second phase of dissociation occurring after the Auger decay. We suggest that this difference is due to the Auger decay, which can or cannot redistribute the initially created vacancy in the molecule, depending on the molecular type and on time passed before the decay that allowed the molecule to reach a certain $\mathrm{C}-\mathrm{Cl}$ distance. As seen in Fig. 7, initially $\mathrm{CHCl}_{3}$ and $\mathrm{CCl}_{4}$ experience a larger charge deficit on the coreexcited chlorine. As the $\mathrm{C}-\mathrm{Cl}$ distance increases, they interact with the rest of the molecule and draw the negative charge from the other atoms. This indicates that the system is able to interact more strongly, or interact until much later times than is possible for the $\mathrm{CH}_{3} \mathrm{Cl}$ and $\mathrm{CH}_{2} \mathrm{Cl}_{2}$ cases, so that the Auger decay might be able to redistribute larger amount of charge.

After $6.5 \mathrm{fs}$, approximately $65 \%$ of the population has decayed by resonant Auger. This is plotted in Fig. 7 with a vertical line. We consider this distance to be an estimate for the distance at which there no longer would be any major vacancy transfers in the $\mathrm{CH}_{3} \mathrm{Cl}$ molecule despite Auger decay happening at later times. According to the total $\mathrm{Cl}^{+} \mathrm{CIY}$ (see Table III), about $32 \%$ of cases end up a in situation where the charge is located in the chlorine atom which supports the fact that alternatively there are vacancy transfers in $68 \%$ of cases. This percentage is very close to the population that has decayed by RA after $6.5 \mathrm{fs}$. According to our observations, the corresponding distances in $\mathrm{CH}_{3} \mathrm{Cl}$ and $\mathrm{CCl}_{4}$ would be much larger, well beyond the reconnection point, where the nuclear movements become more complicated.

\section{v. CONCLUSIONS}

We have performed electron-ion coincidence experiments on four different chlorinated methanes at the $\mathrm{Cl} 2 p_{3 / 2}$ $\rightarrow \sigma^{*}$ resonance and observe varying fragmentation pathways for similar products. Special interest was given to the $\mathrm{Cl}^{+}$ fragment. It was discovered that in the lightest chlorinated methanes, $\mathrm{CH}_{3} \mathrm{Cl}$ and $\mathrm{CH}_{2} \mathrm{Cl}_{2}$, the chlorine cation is observed to appear in coincidence with the RA final states that are similar to atomic chlorine. Previously, this behavior has been attributed to the ultrafast nuclear motion in the molecule, where the Auger decay occurs in the core-excited chlorine atom that has a considerable distance to the rest of the molecule. Our computational results indicate that there indeed is a strongly repulsive potential energy surface that can induce fast nuclear motion. Curiously, however, our results indicate that in the $\mathrm{CHCl}_{3}$ and $\mathrm{CCl}_{4}$ molecules there exists a similar, equally repulsive potential energy surface in the core-excited state. The experimental results for the $\mathrm{CH}_{3} \mathrm{Cl}$ and $\mathrm{CCl}_{4}$ cases, however, differ considerably, as the $\mathrm{Cl}^{+}$signal is one of the weakest detected ions in coincidence with the same resonant Auger final states.

We can tentatively explain the great difference in the $\mathrm{Cl}^{+}$ ion appearance as the difference in the most probable Auger final state that might redistribute the vacancy in the coreexcited chlorine. It is possible that in $\mathrm{CH}_{3} \mathrm{Cl}$ and $\mathrm{CH}_{2} \mathrm{Cl}_{2}$ cases, vacancy in the valence shells created by the resonant Auger decay might be located in the vicinity of the $\mathrm{Cl}$ atom for long enough and that the charge-interaction between the chlorine and the rest of the molecule is inefficient. Therefore what we can observe is the $\mathrm{Cl}^{+}$ion. In the $\mathrm{CHCl}_{3}$ and $\mathrm{CCl}_{4}$ cases, this same charge interaction must either take place more efficiently when the $\mathrm{C}-\mathrm{Cl}$ distance is still relatively small, or the interaction is still possible for a longer time than in the lighter chlorinated methane cases. To verify this, detailed Auger decay rate calculations would be needed for molecular excited states evolving along the dissociation potential energy curve.

It is therefore evident that to properly attribute ultrafast dissociation to a particular resonance excitation in a molecule, detailed information on the nuclear dynamic and Auger decay rate calculations is needed. Knowledge of the potential energy surfaces is required and extremely useful, but they alone cannot be combined with the atomic Auger lifetimes to be able to deduce whether UFD is an efficient process, as we have demonstrated here.

\section{ACKNOWLEDGMENTS}

Staff of the MAX IV Laboratory are acknowledged for assistance in the I411 beamline operation. The work is financially supported by an Oulu University Strategic Grant, the No. P1-0112 research program of the Slovenian Research Agency, the North Ostrobothnia Regional fund of the Finnish Cultural Foundation, and the Research Council for Natural Sciences and Engineering of the Academy of Finland. The research leading to these results has also received funding from the European Community's Seventh Framework Programme (No. FP7/2007-2013) CALIPSO under Grant Agreement No. 312284. The authors wish to thank J. A. Kettunen for his work in performing preparatory experiments.

${ }^{1}$ A. M. Holloway and R. P. Wayne, in Atmospheric Chemistry (The Royal Society of Chemistry, 2010), Chap. 11.

${ }^{2}$ M. Khalil and R. Rasmussen, Atmos. Environ. 33, 1305 (1999).

${ }^{3}$ M. Khalil and R. Rasmussen, Atmos. Environ. 33, 1151 (1999).

${ }^{4}$ L. Hu, S. A. Montzka, B. R. Miller, A. E. Andrews, J. B. Miller, S. J. Lehman, C. Sweeney, S. M. Miller, K. Thoning, C. Siso, E. L. Atlas, D. R. Blake, J. de Gouw, J. B. Gilman, G. Dutton, J. W. Elkins, B. Hall, H. Chen, M. L. Fischer, M. E. Mountain, T. Nehrkorn, S. C. Biraud, F. L. Moore, and P. Tans, Proc. Natl. Acad. Sci. U. S. A. 113, 2880 (2016).

${ }^{5}$ E. C. Leedham Elvidge, D. E. Oram, J. C. Laube, A. K. Baker, S. A. Montzka, S. Humphrey, D. A. O'Sullivan, and C. A. M. Brenninkmeijer, Atmos. Chem. Phys. 15, 1939 (2015).

${ }^{6}$ G. W. Gribble, Naturally Occurring Organohalogen Compounds-A Comprehensive Update, Volume 91 of Fortschritte der Chemie Organischer Naturstoffe/Progress in the Chemistry of Organic Natural Products (Springer Vienna, Vienna, 2010).

${ }^{7}$ P. Morin and I. Nenner, Phys. Rev. Lett. 56, 1913 (1986).

${ }^{8}$ P. Morin and C. Miron, J. Electron Spectrosc. Relat. Phenom. 185, 259 (2012).

${ }^{9}$ O. Travnikova, T. Marchenko, G. Goldsztejn, K. Jänkälä, N. Sisourat, S. Carniato, R. Guillemin, L. Journel, D. Céolin, R. Püttner, H. Iwayama, E. Shigemasa, M. N. Piancastelli, and M. Simon, Phys. Rev. Lett. 116, 213001 (2016).

${ }^{10}$ R. Thissen, M. Simon, and M. Hubin-Franskin, J. Chem. Phys. 101, 7548 (1994).

${ }^{11}$ D. L. Hansen, J. Cotter, G. R. Fisher, K. T. Leung, R. Martin, P. Neill, R. C. C. Perera, M. Simon, Y. Uehara, B. Vanderford, S. B. Whitfield, and D. W. Lindle, J. Phys. B: At., Mol. Opt. Phys. 32, 2629 (1999). 
${ }^{12}$ E. Fainelli, F. Maracci, R. Platania, and L. Avaldi, J. Electron Spectrosc. Relat. Phenom. 119, 81 (2001)

${ }^{13}$ A. F. Lago, J. Z. Dávalos, U. Kerdpin, and A. S. Schlachter, J. Phys. Chem. A 110, 13717 (2006).

${ }^{14}$ A. Lago, A. Santos, and G. de Souza, Int. J. Mass Spectrom. 262, 187 (2007).

${ }^{15}$ A. Santos, J. Maciel, and G. de Souza, J. Electron Spectrosc. Relat. Phenom. 156-158, 236 (2007).

${ }^{16}$ D. Céolin, M. N. Piancastelli, R. Guillemin, W. C. Stolte, S.-W. Yu, O. Hemmers, and D. W. Lindle, J. Chem. Phys. 126, 084309 (2007).

${ }^{17}$ E. Kokkonen, M. Vapa, K. Bučar, K. Jänkälä, W. Cao, M. Žitnik, and M. Huttula, Phys. Rev. A 94, 033409 (2016).

${ }^{18}$ I. Novak, J. Benson, and A. Potts, J. Electron Spectrosc. Relat. Phenom. 41, 225 (1986).

${ }^{19}$ T. N. Olney, W. Fat Chan, G. Cooper, C. Brion, and K. Tan, J. Electron Spectrosc. Relat. Phenom. 66, 83 (1993).

${ }^{20}$ W. von Niessen, L. Åsbrink, and G. Bieri, J. Electron Spectrosc. Relat. Phenom. 26, 173 (1982).

${ }^{21}$ R. Locht, B. Leyh, A. Hoxha, D. Dehareng, K. Hottmann, H. Jochims, and H. Baumgärtel, Chem. Phys. 272, 293 (2001).

${ }^{22}$ D. Holland, I. Powis, G. Öhrwall, L. Karlsson, and W. von Niessen, Chem. Phys. 326, 535 (2006).

${ }^{23}$ R. Tuckett, J. Harvey, P. Hemberger, and A. Bodi, J. Mol. Spectrosc. 315, $172(2015)$.

${ }^{24}$ K. T. Lu, J. M. Chen, J. M. Lee, S. C. Haw, S. A. Chen, Y. C. Liang, and S. W. Chen, Phys. Rev. A 82, 033421 (2010).

${ }^{25}$ K. F. Alcantara, A. B. Rocha, A. H. A. Gomes, W. Wolff, L. Sigaud, and A. C. F. Santos, J. Phys. Chem. A 120, 6728 (2016).

${ }^{26}$ K. T. Lu, J. M. Chen, J. M. Lee, S. C. Haw, Y. C. Liang, and M. J. Deng, J. Chem. Phys. 135, 044303 (2011).

${ }^{27}$ K. T. Lu, J. M. Chen, J. M. Lee, C. K. Chen, T. L. Chou, and H. C. Chen, New J. Phys. 10, 053009 (2008).

${ }^{28}$ R. Bohinc, M. Žitnik, K. Bučar, M. Kavčič, L. Journel, R. Guillemin, T. Marchenko, M. Simon, and W. Cao, J. Chem. Phys. 139, 134302 (2013).

${ }^{29}$ R. Bohinc, M. Žitnik, K. Bučar, and M. Kavčič, J. Chem. Phys. 140, 164304 (2014).

${ }^{30}$ M. N. Piancastelli, G. Goldsztejn, T. Marchenko, R. Guillemin, R. K. Kushawaha, L. Journel, S. Carniato, J.-P. Rueff, D. Céolin, and M. Simon, J. Phys. B: At., Mol. Opt. Phys. 47, 124031 (2014).

${ }^{31}$ M. Žitnik, M. Kavčič, R. Bohinc, K. Bučar, A. Mihelič, W. Cao, R. Guillemin, L. Journel, T. Marchenko, S. Carniato, E. Kawerk, M. Piancastelli, and M. Simon, J. Electron Spectrosc. Relat. Phenom. 204, 356 (2015).

${ }^{32}$ R. Bohinc, M. Žitnik, K. Bučar, M. Kavčič, S. Carniato, L. Journel, R. Guillemin, T. Marchenko, E. Kawerk, M. Simon, and W. Cao, J. Chem. Phys. 144, 134309 (2016).

${ }^{33}$ C. Miron, P. Morin, D. Céolin, L. Journel, and M. Simon, J. Chem. Phys. 128, 154314 (2008).

${ }^{34}$ M. Bässler, J.-O. Forsell, O. Björneholm, R. Feifel, M. Jurvansuu, S. Aksela, S. Sundin, S. Sorensen, R. Nyholm, A. Ausmees, and S. Svensson, J. Electron Spectrosc. Relat. Phenom. 101-103, 953 (1999).

${ }^{35}$ M. Bässler, A. Ausmees, M. Jurvansuu, R. Feifel, J.-O. Forsell, P. de Tarso Fonseca, A. Kivimäki, S. Sundin, S. Sorensen, R. Nyholm, O. Björneholm, S. Aksela, and S. Svensson, Nucl. Instrum. Methods Phys. Res., Sect. A 469, 382 (2001).
${ }^{36}$ N. Mårtensson, P. Baltzer, P. Brühwiler, J.-O. Forsell, A. Nilsson, A. Stenborg, and B. Wannberg, J. Electron Spectrosc. Relat. Phenom. 70, 117 (1994).

${ }^{37}$ W. C. Wiley and I. H. McLaren, Rev. Sci. Instrum. 26, 1150 (1955).

${ }^{38}$ O. Jagutzki, A. Cerezo, A. Czasch, R. Dorner, M. Hattas, M. Huang, V. Mergel, U. Spillmann, K. Ullmann-Pfleger, T. Weber, H. SchmidtBocking, and G. D. W. Smith, IEEE Trans. Nucl. Sci. 49, 2477 (2002).

${ }^{39}$ E. Kukk, R. Sankari, M. Huttula, A. Sankari, H. Aksela, and S. Aksela, J. Electron Spectrosc. Relat. Phenom. 155, 141 (2007).

${ }^{40}$ M. Huttula, S. Heinäsmäki, H. Aksela, E. Kukk, and S. Aksela, J. Electron Spectrosc. Relat. Phenom. 156-158, 270 (2007).

${ }^{41}$ J. Kettunen, J. Niskanen, M. Huttula, M. Vapa, S. Urpelainen, and H. Aksela, J. Mass Spectrom. 46, 901 (2011).

${ }^{42}$ J. A. Kettunen, S. Urpelainen, S. Heinäsmäki, and M. Huttula, Phys. Rev. A 86, 023201 (2012).

${ }^{43}$ J. A. Kettunen, A. Sankari, L. Partanen, S. Urpelainen, A. Kivimäki, and M. Huttula, Phys. Rev. A 85, 062703 (2012).

${ }^{44}$ E. Kokkonen, T. Löytynoja, K. Jänkälä, J. A. Kettunen, S. Heinäsmäki, A. Karpenko, and M. Huttula, J. Chem. Phys. 140, 184304 (2014).

${ }^{45}$ E. Kokkonen, T. Löytynoja, L. Hautala, K. Jänkälä, and M. Huttula, J. Chem. Phys. 143, 074307 (2015).

${ }^{46}$ G. Prümper and K. Ueda, Nucl. Instrum. Methods Phys. Res., Sect. A 574, 350 (2007).

${ }^{47}$ H. Sann, T. Havermeier, C. Müller, H.-K. Kim, F. Trinter, M. Waitz, J. Voigtsberger, F. Sturm, T. Bauer, R. Wallauer, D. Schneider, M. Weller, C. Goihl, J. Tross, K. Cole, J. Wu, M. S. Schöffler, H. Schmidt-Böcking, T. Jahnke, M. Simon, and R. Dörner, Phys. Rev. Lett. 117, 243002 (2016).

${ }^{48}$ O. Björneholm, S. Sundin, S. Svensson, R. Marinho, A. Naves de Brito, F. Gel'mukhanov, and H. Ågren, Phys. Rev. Lett. 79, 3150 (1997).

${ }^{49}$ E. Kukk, H. Aksela, O.-P. Sairanen, S. Aksela, A. Kivimäki, E. Nõmmiste, A. Ausmees, A. Kikas, S. J. Osborne, and S. Svensson, J. Chem. Phys. 104, 4475 (1996)

${ }^{50}$ A. F. Lago, A. C. F. Santos, and G. G. B. de Souza, J. Chem. Phys. 120, 9547 (2004)

${ }^{51}$ C. Miron and P. Morin, Nucl. Instrum. Methods Phys. Res., Sect. A 601, 66 (2009).

${ }^{52}$ T. Ohta and H. Kuroda, Bull. Chem. Soc. Jpn. 49, 2939 (1976).

${ }^{53}$ J. Harvey, R. P. Tuckett, and A. Bodi, Phys. Chem. Chem. Phys. 16, 20492 (2014).

${ }^{54}$ F. Neese, Wiley Interdiscip. Rev.: Comput. Mol. Sci. 2, 73 (2012).

${ }^{55}$ J. D. Dow, D. R. Franceschetti, P. C. Gibbons, and S. E. Schnatterly, J. Phys. F: Met. Phys. 5, L211 (1975).

${ }^{56}$ C. T. Chen, Y. Ma, and F. Sette, Phys. Rev. A 40, 6737 (1989).

${ }^{57}$ O. Travnikova, V. Kimberg, R. Flammini, X.-J. Liu, M. Patanen, C. Nicolas, S. Svensson, and C. Miron, J. Phys. Chem. Lett. 4, 2361 (2013).

${ }^{58}$ F. Weigend and R. Ahlrichs, Phys. Chem. Chem. Phys. 7, 3297 (2005).

${ }^{59}$ A. Menzel, B. Langer, J. Viefhaus, S. Whitfield, and U. Becker, Chem. Phys. Lett. 258, 265 (1996).

${ }^{60}$ K. Hermann, L. G. M. Pettersson, M. E. Casida, C. Daul, A. Goursot, A. Koester, E. Proynov, A. St-Amant, and D. R. Salahub, contributing authors: V. Carravetta, H. Duarte, C. Friedrich, N. Godbout, J. Guan, C. Jamorski, M. Leboeuf, M. Leetmaa, M. Nyberg, S. Patchkovskii, L. Pedocchi, F. Sim, L. Triguero, and A. Vela, StoBe-deMon version 3.1 (2011).

${ }^{61}$ J. C. Slater and K. H. Johnson, Phys. Rev. B 5, 844 (1972).

${ }^{62} \mathrm{R}$. Bohinc, "X-ray studies of structural and dynamical properties of chlorinated hydrocarbons," Ph.D. thesis, University of Ljubljana, 2014 